\title{
Knowledge, Attitude, and Practice Survey of Dentists in Palestine toward Deep Dentin Caries Removal
}

\author{
Tarek Rabi
}

\section{ABSTRACT}

Aims: The objective of this study was to assess the knowledge, attitude, and practice of dentists in Palestine toward deep dentin caries removal and the associated restorative strategies preferred.

Materials and methods: The study was conducted through an online survey among the dentists registered with the Palestinian Dental Association. A total of 300 dentists were administered a structured, self-administered questionnaire to assess their knowledge, attitude, and practice toward deep dentin caries removal. The questionnaire consisted of an eight-item written survey instrument constructed for the survey purpose.

Results: Among the 300 dentists, 201 dentists responded to the survey with a response rate of $67 \%$. Hardness of remaining dentin was the most important criterion employed to assess excavation. To treat an exposed pulp, $74 \%$ of dentists considered direct capping, whereas $79 \%$ refuted partial excavation fearing caries progression or pulp damage. To facilitate restoration longevity, $56.6 \%$ reported preferring more invasive treatment. Only $16 \%$ reported that they would prefer a step-wise caries excavation.

Conclusion: A higher percentage of surveyed dentists were skeptical about leaving caries during excavation, and they did not prefer incomplete caries removal. Direct pulp capping was the preferred treatment strategy when pulp exposure occurred.

Clinical significance: The beneficence of partial excavation should be highlighted in under- and postgraduate education in Palestine. It would pave the way to promote minimally invasive techniques in restorative dentistry.

Keywords: Deep dentin caries removal, Dental pulp capping, Dental pulp exposure, Palestine, Restorative dentistry, Step-wise caries excavation.

How to cite this article: Rabi T. Knowledge, Attitude, and Practice Survey of Dentists in Palestine toward Deep Dentin Caries Removal. Cons Dent Endod J 2016;1(2):28-32.

Source of support: Nil

Conflict of interest: None

\section{INTRODUCTION}

The strategy for deep dentin caries management has always been an enigma for the restorative dentist. The

Lecturer

Department of Operative Dentistry, Al-Quds University, Abu Dis Jerusalem, Israel

Corresponding Author: Tarek Rabi, Lecturer, Department of Operative Dentistry, Al-Quds University, Abu Dis, Jerusalem Israel, Phone: +9725224441, e-mail: tarekrabi@gmail.com age-old consensus that mandates attempted eradication of bacteria and all infected dental biomass and subsequent restoration has been debated by new philosophers who have contemplated the benefits of avoiding the potential complications of complete excavation of carious dentin close to the pulp. There is growing evidence supporting the incomplete removal of carious tissue before the cavity is restored. ${ }^{1}$ Suppositionally, it is argued that a completely sealed remaining caries lesion should be arrested. Hence, therapy of cavitated lesions may require less focus on complete excavation than on adequate restorations. ${ }^{2,3}$

This paradigm shift was based on a new understanding toward the disease. Currently, caries is seen as a result of an ecologic shift within the dental biofilm to acidogenic and aciduric bacterial species, frequently created and maintained by abundant dietary fermentable carbohydrates. The pathologic alteration of the $\mathrm{pH}$ leads to an imbalance between de- and re-mineralization, and extensively de-mineralized dental substance eventually cavitates and leads to clinical "decay"., 2,4,5 From time immemorial, dentists have removed all infected enamel and dentin using excavators or high- and lowspeed instruments, and thereby risking exposure of the pulp. Instead of attempting to remove all bacteria, it should be sufficient to re-shift the ecologic and metabolic balance within the biofilm, thus promoting re-mineralization, thereby arresting the caries lesions. ${ }^{6}$ A plethora of studies investigating the sealing of fissure caries has demonstrated such effects. They showed a reduction in the bacterial number and activity and the clinical, microbiological, and radiological signs of caries inactivation and dentin re-mineralization. ${ }^{7}$ Nevertheless, a range of treatment concepts, like caries sealing with resins or crowns ${ }^{8,9}$ or caries infiltration, ${ }^{10}$ successfully use the described inactivation and re-mineralization effects. Although newer concepts and consensus emerge on one hand, it is the practicing dentists who need to apply such novel concepts in the day-to-day practice on the other hand. Very few studies exist that assessed the attitude and practice of dentists when comes to deep dentin caries removal, and there are no studies assessing the same in Palestine. Hence, the aim of this study is to assess the knowledge, attitude, and practice of dentists in Palestine toward deep dentin caries removal and the associated restorative strategies preferred. 
Knowledge, Attitude, and Practice Survey of Dentists in Palestine toward Deep Dentin Caries Removal

Table 1: Chosen criteria to assess and methods to perform excavation of deep dentin caries

\begin{tabular}{|c|c|c|c|c|}
\hline \multicolumn{5}{|c|}{ Which criteria do you use to assess sufficient removal of primary caries close to the pulp? } \\
\hline Hardness & $41 \%$ hard & $10 \%$ soft & $40 \%$ leathery & $8 \%$ not relevant \\
\hline Color & $54 \%$ very discolored & $13 \%$ slightly discolored & $25 \%$ not discolored & $8 \%$ not relevant \\
\hline Moist & $70 \%$ dry & $21 \%$ slightly moist & $10 \%$ not relevant & $0 \%$ wet \\
\hline Excavation & $52 \%$ hand excavator & $31 \%$ rosehead metal bur & $\begin{array}{l}9 \% \text { ceramic rosehead bur } \\
5 \% \text { polymeric rosehead bur }\end{array}$ & $3 \%$ chemicals \\
\hline Further criteria & $7 \%$ caries activator tests & & & \\
\hline
\end{tabular}

\section{MATERIALS AND METHODS}

The study was conducted through an online survey among the dentists registered with the Palestinian Dental Association. A total of 300 dentists were administered a structured, self-administered questionnaire to assess their knowledge, attitude, and practice toward deep dentin caries removal. The questionnaire was used in a previous study by Schwendicke et $\mathrm{al}^{11}$ consisted of an eight-item written survey instrument constructed for the survey purpose. Among the 300 dentists requested for the survey, 201 dentists responded with a response rate of $67 \%(n=201)$.

The eight-item written survey instrument analyzed the following eight criteria: (1) Criteria to assess sufficient removal of primary caries close to the pulp if pulp exposure is likely, (2) excavation methods and cavity treatment before adhesive restoration, (3) treatment of choice to remove caries in proximity to the pulp in a vital tooth of a 20-year-old patient, (4) expected success rates of direct capping, root canal treatment, and incomplete or stepwise excavation, (5) attitudes regarding complete and incomplete caries removal and reasons for these attitudes, (6) attitudes regarding treatment priorities: Restoration longevity vs invasiveness of treatment, (7) influence of legal regulations, and (8) monitor or re-treat an asymptomatic tooth with a radiolucency under the restoration in proximity to the pulp. Consistency, color, moisture, and further criteria were used to assess the dentist's preference for sufficient removal of primary caries close to the pulp if pulp exposure is likely. The dentist's practice of deep dentin removal was assessed using yes/no response questions. The dentists' attituderelated questions regarding treatment and restorative strategies were measured using five-point Likert response scale, which ranged from strongly agree to strongly disagree. $^{12}$

\section{STATISTICAL ANALYSIS}

The statistical analysis was performed using Statistical Package for the Social Sciences (SPSS) software version 16. Demographic data, such as the name, age, gender, type of clinical practice along with their knowledge, attitude, and practice scores toward deep dentin caries removal were assessed and the percentage of dentists falling under different treatment modalities were segregated. Also the descriptive statistics was performed for each question used as the survey tool.

\section{RESULTS}

Among the 300 dentists, 201 dentists responded to the survey with a response rate of $67 \%(n=201)$. Demographic data presented that $45 \%$ were males, and $55 \%$ were females. $98 \%$ of them belonged to private practice, whereas $2 \%$ belonged to the public practice. The vast majority of dentists stated that they used two or more criteria to assess caries removal close to the pulp, with hardness of the remaining dentin being the most frequently used criterion $(41 \%)$. Only a few dentists used chemo-mechanical excavation or ceramic/polymeric burs to excavate caries. A majority preferred hand excavators for the same (Table 1). To adhesively restore deep cavities, only $2 \%$ of dentists reported not using any liner but placing the bonding directly onto the dentin. A very high percentage of dentists $(72 \%)$ declared using a form of calcium hydroxide. Of these, 40 and $2 \%$ used calcium hydroxide cement and suspension respectively, and $30 \%$ both. It was followed by Vitrebond (3M ESPE, MN, USA) being used by 39\% followed by others, such as IRM (Dentsply Caulk) and Theracal (Bisco Inc., Schamburg, IL, USA) (Graph 1).

Dentists were asked to assign expected 2-year success rates to certain treatments associated with caries removal

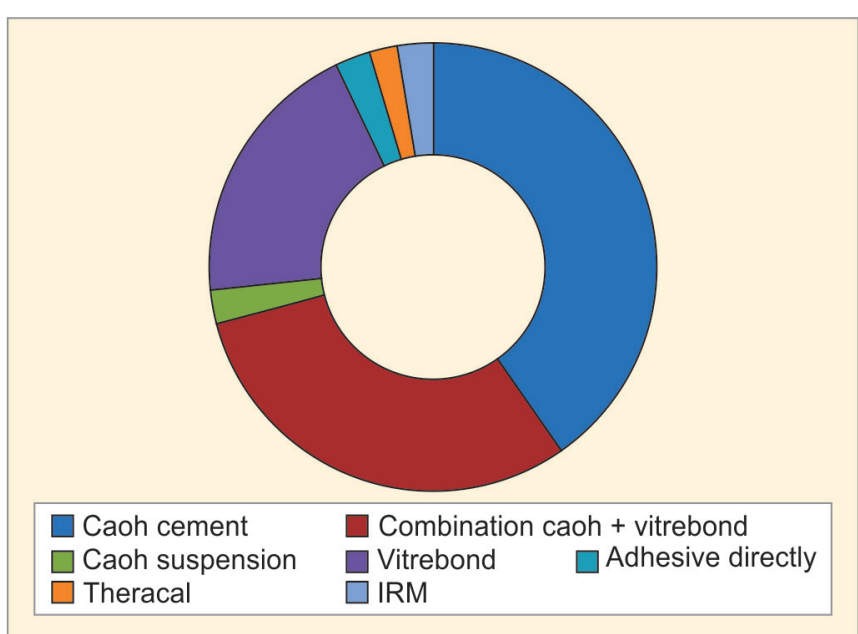

Graph 1: Percentage of preferred liners by dentists for deep caries management 




Graph 2: Percentage of dentists who assumed respective 2-year survival rates of several treatment options for deep dentin caries

in the proximity of the pulp in a 20-year-old patient (Graph 2). A total of $59.7 \%$ believed that indirect capping had higher survival rates of 81 to $100 \% .33 .3$ and $30.8 \%$ of the dentists voted incomplete excavation to have survival rates as low as 0 to $20 \%$ and 21 to $40 \%$ success rates, respectively. If faced with a 20 -year-old patient with deep dentin caries with the risk of pulp exposure and several possible treatment options, $79 \%$ considered complete excavation, even if pulp exposure was likely. $21 \%$ only found incomplete excavation an option to avoid exposing the pulp. If pulp exposure occurred, $74 \%$ of dentists would perform direct capping. One-step excavation was the preferable choice for $24 \%$ of dentists who considered incomplete caries removal, while only $16 \%$ of dentists would provide incomplete two-step excavation (Graph 3). While 56.6\% reported preferring more invasive treatment to facilitate restoration longevity, $60.9 \%$ reported to prefer less invasive methods and accept possible re-treatment (Table 2).

\section{DISCUSSION}

In this study, the authors were able to infer that the majority of the dentists refused to leave caries under a restoration which was reflected by $>50 \%$ agreement toward the removal of caries and cariogenic organisms. Also, 33.3 and $30.8 \%$ of the dentists suggested incomplete

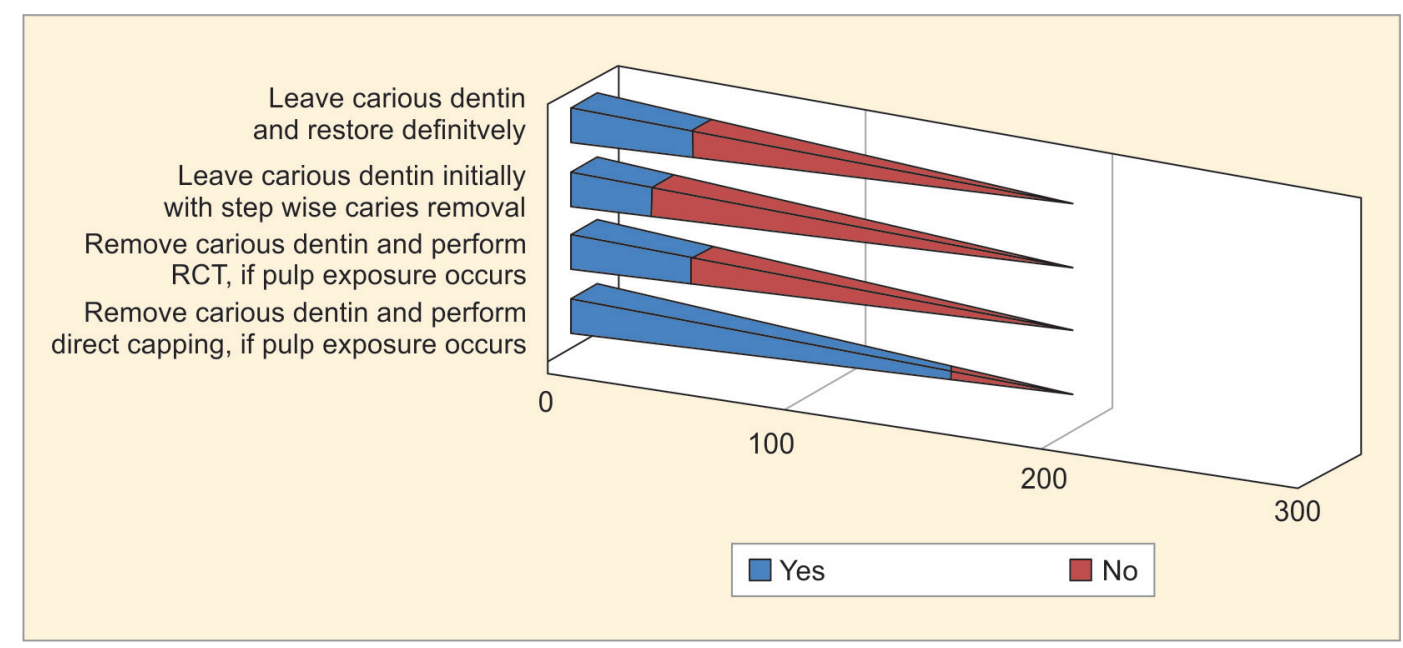

Graph 3: Attitude toward deep dentin caries removal

Table 2: Attitudes of dentists toward leaving caries under a restoration and restorative treatment strategies

\begin{tabular}{|c|c|c|c|c|}
\hline & Strongly disagree & Disagree & Agree & Strongly agree \\
\hline \multicolumn{5}{|l|}{ Leaving caries under restorations } \\
\hline $\begin{array}{l}\text { Cariogenic microorganisms need to be removed completely since caries } \\
\text { might progress otherwise }\end{array}$ & $23.9 \%$ & $20.4 \%$ & $18.9 \%$ & $36.8 \%$ \\
\hline $\begin{array}{l}\text { Certain amounts of cariogenic microorganisms can be left since intact } \\
\text { restorations can seal and thus arrest caries }\end{array}$ & $33.3 \%$ & $40.8 \%$ & $16.4 \%$ & $9.5 \%$ \\
\hline $\begin{array}{l}\text { Caries should always be removed completely since residual caries is a risk } \\
\text { for the vitality of the pulp }\end{array}$ & $6.9 \%$ & $9.5 \%$ & $12.4 \%$ & $71.1 \%$ \\
\hline $\begin{array}{l}\text { Caries in proximity to the pulp should be left to avoid pulp exposure } \\
\text { Restorative strategy/treatment priority }\end{array}$ & $59.2 \%$ & $17.4 \%$ & $13.4 \%$ & $9.9 \%$ \\
\hline I prefer invasive methods if this enhances restoration survival & $12.4 \%$ & $30.8 \%$ & $34.3 \%$ & $22.3 \%$ \\
\hline I prefer less invasive methods and accept possible re-treatment & $22.3 \%$ & $17.4 \%$ & $44.7 \%$ & $15.4 \%$ \\
\hline $\begin{array}{l}\text { Regulations enforce rather invasive methods to avoid re-treatment within } \\
\text { guarantee time }\end{array}$ & $31.3 \%$ & $48.7 \%$ & $11.4 \%$ & $8.4 \%$ \\
\hline
\end{tabular}


excavation to have survival rates as low as 0 to $20 \%$ and 21 to $40 \%$ success rates respectively. The previous notion that residual caries might progress or harm the pulp could have influenced this decision. Nevertheless, in this study, the dentists were aware of success rates for direct (60-80\%) and indirect capping (81-100\%) or root canal treatment (60-80\%), which were moderately associated with chosen treatment. Despite limited expectations regarding its success, many dentists considered performing direct capping (74\%) to $58.7 \%$ who preferred indirect pulp capping. Irrespective of the beliefs and practices of the dentists, an array of recent systematic reviews supports incomplete excavation.

A systematic Cochrane review demonstrated possible benefits of incomplete over complete caries removal. ${ }^{13}$ A recent systematic review published in 2013 confirmed that incomplete caries removal seemed advantageous when compared to complete excavation, especially when in proximity to the pulp. ${ }^{14}$ Another systematic review provided strong evidence for the advisability of leaving behind infected dentin, the removal of which would put the pulp at risk of exposure. ${ }^{15}$ It is demonstrated that cariogenic bacteria, once isolated from their source of nutrition by a restoration of sufficient integrity, either die or remain dormant and thus pose no risk to the health of the dentition. With regards to the excavation of enamel and dentin in deep carious lesions, there exists ambiguity. The amount of carious dentin left is variable: Some studies removed just enamel and did not excavate at all within dentin ${ }^{16,17}$; others reported removal of affected enamel and some dentin, leaving soft and moist carious mass on the floor. ${ }^{18,19}$

Most studies left only a thin layer of carious substance above the pulp, thus creating a more or less leathery surface. This technique, often combined with the use of liners on the pulpal wall, has been called indirect pulp capping or indirect pulp treatment. ${ }^{20,21}$ In accordance to the aforementioned studies, $72 \%$ admitted to the usage of liners, preferably calcium hydroxide-based liners (40 and $2 \%$ calcium hydroxide cement and suspension; $30 \%$ both).

In this study, it was noted that one-step excavation (24\%) was more preferred than two-step excavation, in those who preferred incomplete excavation (16\%). It could be due to the reason of many recent reports showing higher success for one-step excavation. The advantage of one-step compared to two-step caries removal in terms of pulpal exposure was also confirmed by a recent randomized trial. ${ }^{22,23}$ These studies reported significantly higher success rates of one-step incomplete compared with stepwise excavation. It remains unclear if longer intervals between first and second visits could reduce the risks of pulpal exposure and complications, or if certain liners or restorative materials are advantageous to maintain pulp vitality. ${ }^{24-26}$

\section{CONCLUSION}

This study emphasizes the need of the hour to expose the dentists to the recent research conducted on deep dentin caries removal. A higher percentage of surveyed dentists were skeptical about leaving caries during excavation, and they did not prefer incomplete caries removal. Direct pulp capping was the preferred treatment strategy when pulp exposure occurred. With concepts emerging based on latest scientific consensus reports, it would be advisable for the dentists to update and adhere to these novel concepts in order to improve their clinical practice. The beneficence of partial excavation should be highlighted in undergraduate and postgraduate levels in Palestine. It will result in the resurgence of minimally invasive techniques in the field of restorative dentistry.

\section{REFERENCES}

1. Banerjee A, Watson TF, Kidd EA. Dentin caries: take it or leave it? S Afr Dent J 2001;56(4):189-192.

2. Kidd EA. How 'clean' must a cavity be before restoration? Caries Res 2004 May-Jun;38(3):305-313.

3. Ricketts D. Restorative dentistry: management of the deep carious lesion and the vital pulp dentin complex. Br Dent J 2001 Dec;191(11):606-610.

4. Kidd EA, Fejerskov O. What constitutes dental caries? Histopathology of carious enamel and dentin related to the action of cariogenic biofilms. J Dent Res 2004;83 Spec C: C35-C38.

5. Marsh PD. Dental plaque as a biofilm and a microbial community-implications for health and disease. BMC Oral Health 2006;6 (Suppl 1):S14.

6. Bjorndal L, Kidd E. The treatment of deep dentin caries lesions. Dent Update 2005 Sep;32(7):402-404, 407-410, 413.

7. Oong EM, Griffin SO, Kohn WG, Gooch BF, Caufield PW. The effect of dental sealants on bacteria levels in caries lesions. J Am Dent Assoc 2008 Mar;139(3):271-278.

8. Griffin SO, Oong E, Kohn W, Vidakovic B, Gooch BF, Bader J, Clarkson J, Fontana MR, Meyer DM, Rozier RG, et al. The effectiveness of sealants in managing caries lesions. J Dent Res 2008 Feb;87(2):169-174.

9. Innes NP, Evans DJ, Stirrups DR. Sealing caries in primary molars: randomized control trial, 5-year results. J Dent Res 2011 Dec;90(12):1405-1410.

10. Paris $S$, Hopfenmuller W, Meyer-Lueckel H. Resin infiltration of caries lesions. J Dent Res 2010 Aug;89(8):823-826.

11. Schwendicke F, Meyer-Lueckel H, Dörfer CE, Paris S. Attitudes and behaviour regarding deep dentin caries removal-a survey among German dentists. Caries Res 2013;47(6):566-573.

12. Likert R. A technique for the measurement of attitudes. Arch Psychol 1932;22(140):1-55.

13. Ricketts D, Kidd E, Innes N, Clarkson JE. Complete or ultraconservative removal of decayed tissue in unfilled teeth. Cochrane Database Syst Rev 2006 Jul;(3):CD003808. 
14. Schwendicke F, Dorfer CE, Paris S. Incomplete caries removal: a systematic review and metaanalysis. J Dent Res 2013 Apr;92(4):306-314.

15. Craig RG, Curro FA, Green WS, Ship JA. Treatment of deep carious lesions by complete excavation or partial removal: a critical review. J Am Dent Assoc 2008 Jun 30;139(6): 705-712.

16. Mertz-Fairhurst EJ, Curtis JW, Ergle JW, Rueggeberg FA, Adair SM. Ultraconservative and cariostatic sealed restorations: results at year 10. J Am Dent Assoc 1998 Jan;129(1):55-66.

17. Phonghanyudh A, Phantumvanit P, Songpaisan $Y$, Petersen PE. Clinical evaluation of three caries removal approaches in primary teeth: a randomized controlled trial. Community Dent Health 2012 Jun;29(2):173-178.

18. Lula EC, Monteiro-Neto V, Alves CM, Ribeiro CC. Microbiological analysis after complete or partial removal of carious dentin in primary teeth: a randomized clinical trial. Caries Res 2009;43(5):354-358.

19. Ribeiro CC, Baratieri LN, Perdigão J, Baratieri NM, Ritter AV. A clinical, radiographic, and scanning electron microscopic evaluation of adhesive restorations on carious dentin in primary teeth. Quintessence Int 1999 Sep;30(9):591-599.
20. Casagrande L, Bento LW, Dalpian DM, García-Godoy F, de Araujo FB. Indirect pulp treatment in primary teeth: 4-year results. Am J Dent 2010 Feb;23(1):34-38.

21. Langeland K, Langeland LK. Indirect capping and the treatment of deep carious lesions. Int Dent J 1968 Jun;18(2):362-380.

22. Maltz M, Jardim JJ, Mestrinho HD, Yamaguti PM, Podesta K, Moura MS, de Paula LM. Partial removal of carious dentin: a multicenter randomized controlled trial and 18-month followup results. Caries Res 2013;47(2):103-109.

23. Maltz M, Garcia R, Jardim JJ, de Paula LM, Yamaguti PM, Moura MS, Garcia F, Nascimento C, Oliveira A, Mestrinho HD. Randomized trial of partial vs stepwise caries removal. J Dent Res 2012 Nov;91(11):1026-1031.

24. Mickenautsch S, Yengopal V, Banerjee A. Pulp response to resin modified glass ionomer and calcium hydroxide cements in deep cavities: a quantitative systematic review. Dent Mater 2010 Aug;26(8):761-770.

25. Miyashita $H$, Worthington $H$, Qualtrough A, Plasschaert A. Pulp management for caries in adults: maintaining pulp vitality. Cochrane Database Syst Rev 2007 Apr 18;(2):CD004484.

26. Yengopal V, Harneker SY, Patel N, Siegfried N. Dental fillings for the treatment of caries in the primary dentition. Cochrane Database Syst Rev 2009 Apr 15;(12):CD004483. 